\title{
Preventive Effect of a Fraxinus Excelsior L Seeds/Fruits Extract on Hepatic Steatosis in Obese Type 2 Diabetic Mice
}

Francisco Gomez-Garcia1, John Flanagan², Olga García-Molina', Violeta Vilaplana-Vivo1, Nuria García-Carrillo', Pascale Fança Berthon², Antoine Bily ${ }^{2}$, Marc Roller ${ }^{2}$, Vicente Vicente Ortega ${ }^{1}$ and Nicolas Issaly ${ }^{3 *}$

${ }^{1}$ University Institute of Aging Research, Faculty of Medicine, University of Murcia, Spain

${ }^{2}$ Naturex SA, Site d'Agroparc BP 1218, 84911 Avignon Cedex 9, France

${ }^{3}$ Naturex Spain SL, Autovía A3, salida 343, Camino de Torrent s/n, 46930 Quart de Poblet (Valencia) Spain

\begin{abstract}
Background: Non-alcoholic fatty liver is recognized as one of harmful consequences of the metabolic syndrome and hepatocytes steatosis is well connected with loss of insulin sensitivity, impaired glucose tolerance and can lead to impaired fasting glucose and type2 diabetes mellitus. Fraxinus excelsior L. seed extract has been used as traditional folk medicine by Mediterranean population and Glucevia ${ }^{\circledR}$, a natural extract of Fraxinus excelsior $\mathrm{L}$. derived from seeds/fruits of the plant and standardized to $10 \%$ Nuzhenide and $\mathrm{Gl} 3$, has been previously reported to regulate glucose homeostasis in healthy overweight people.
\end{abstract}

Methods: The effect of seven-month administration of Glucevia ${ }^{\circledR}$ on liver parameters was investigated in a diabetic mouse strain (BKS ++Lepr $\mathrm{db}(\mathrm{db} / \mathrm{db})$ ). The severity of fatty change and grading of hepatic steatosis were determined by estimating the fat hepatocytes contain in animals fed with a control diet or with a control diet supplemented with $0.07 \%(\mathrm{w} / \mathrm{w})$ of the extract.

Results: Glucevia $\circledast$ was shown to significantly reduce fatty liver in diabetics mice $(-54 \% ; p<0.05)$. A concomitant improvement in alkaline phosphatase (ALP) levels and in aspartate aminotransferase/alanine aminotransferase (AST/ALT) ratio were observed between groups $(p<0.05)$. A significant decrease in insulin plasma level $(-22 \%$; $p<0.05)$ was measured in Glucevia ${ }^{\circledR}$ group leading to an improvement of HOMA-IR between groups $(p<0.001)$ while no significant change of fasting blood glucose was observed between group.

Conclusion: The results observed supports the potential hepatoprotective function of Glucevia $\AA$, which seems to prevent fatty liver formation in type 2 diabetes mice model.

Keywords: Fraxinus excelsior L; Fatty liver; hepatic Steatosis; Type 2 Diabetes

\section{Introduction}

Among the medicinal plants used for the treatment of diabetes, the seeds of the common European ash (Fraxinus excelsior L.) have been identified in ethnobotanical surveys as having anti-diabetic properties [1]. Oral administration of an aqueous extract of Fraxinus excelsior L. was found to inhibit renal glucose reabsorption with hypoglycaemic activity in normal and diabetic rats [2], and the hypoglycaemic effect in mice with type 1 diabetes mellitus has been reported to be independent of insulin secretion [3]. Glucevia ${ }^{\circledR}$, a natural extract from the seeds/ fruits of Fraxinus excelsior L. standardized in the secoiridoid glucosides nuzhenide and Gl3 (US 8293292), belongs to the class of herbal insulin sensitizer. Indeed, the effects of a single dose of Glucevia ${ }^{\circledR}$ have been evaluated on postprandial glycaemia and insulin secretion in nondiabetic healthy individuals and exhibited a significant reduction in the mean area under the plasma time-concentration curve (AUC) for glucose levels without significantly altering insulin secretion [4]. This natural insulin sensitizer property has been checked in a randomized, crossover, double-blind and placebo-controlled 7-week nutritional intervention in non-diabetic overweight/obese healthy subjects [5]. Three weeks Glucevia ${ }^{\circledR}$ administration resulted in a 2-h blood glucose values reduction following an oral glucose tolerance test (OGTT), while no significant changes were found in the control period. A significant lower incremental glucose area under the curve has been shown with the extract while treatments were not able to induce significant changes in insulin levels. More interesting, administration of Glucevia ${ }^{\mathbb{R}}$ significantly decreased fat mass compared to vehicle and increased the adiponectin:leptin ratio suggesting its wide range of targets. In vitro, isolated secoiridoid glucosides including nuzhenide, Gl3 and Gl5 from Fraxinus excelsior L. extract were found to activate peroxisome proliferator-activated receptor alpha [6]. Moreover, the differentiation of 3T3-L1 mouse embryonic fibroblasts into adipocytes was shown to be inhibited by isolated secoiridoid glucosides of Glucevia ${ }^{\circledR}$. Chronic administration of the extract $(0.5 \%$ of the diet) to mice fed a high fat diet resulted in significantly lower liver weight by $63.6 \%$ and reduction of the incidence of fatty livers by $66.7 \%$ compared to mice fed a highfat diet alone, and authors have first suggested that Glucevia ${ }^{\circledR}$ could prevent against obesity-related hepatic steatosis [7].

Lipid deposition in the hepatocytes is a common pathology observed in overweight individuals and fatty liver can lead to Nonalcoholic Steatohepatitis (NASH) and turn into fibrosis, a common severely complication among type 2 diabetic patients with a high prevalence of CVD $[8,9]$. According to the World Gastroenterology Organisation,

*Corresponding author: Dr. Nicolas Issaly, Naturex SA, Autovia A-3, salida 343, Camino de Torrent s/n, 46930 Quart de Poblet (Valencia) Spain, Tel: +34 9615795 62; E-mail: n.issaly@naturex.com

Received February 10, 2015; Accepted March 19, 2015; Published March 21, 2015

Citation: Garcia FG, Flanagan J, Molina OG, Vivo VV, Carrillo NG, et al. (2015) Preventive Effect of a Fraxinus Exce/sior L Seeds/Fruits Extract on Hepatic Steatosis in Obese Type 2 Diabetic Mice. J Diabetes Metab 6: 527. doi:10.4172/2155 6156.1000527

Copyright: @ 2015 Garcia FG, et al. This is an open-access article distributed under the terms of the Creative Commons Attribution License, which permits unrestricted use, distribution, and reproduction in any medium, provided the original author and source are credited. 
nonalcoholic fatty liver disease (NAFLD) is a condition defined by excessive fat accumulation in the form of triglycerides (steatosis) in the liver [10]. The main therapeutic treatments for type 2 diabetes with clinical evidence of benefits are: (i) bodyweight management with caloric restriction and exercise, (ii) insulin sensitization with different classes of API and (iii) lipid lowering API. In parallel, to prevent healthy population against diabetes and fatty liver, dietary intervention policy plans have been set, especially to manage Impaired Glucose Tolerance (IGT) and Impaired Fasting blood Glucose (IFG) [11].

The broad-ranging effects of Glucevia ${ }^{\circledR}$ were studied in two animal models which are representative of metabolic disorders: spontaneously hypertensive rats (SHR) and obese Zucker rats [12]. A significant reduction in plasma levels of triglycerides accompanied by a reduction in fasting plasma glucose and body weight were found in Zucker rats fed with the extract for 5 weeks. No studies to date have focused on the direct benefits of the extract for prevention of fatty liver. In the present study, we therefore evaluated the effect of a long-term administration diet supplemented with Glucevia ${ }^{\circledR}$ on the development of NAFLD in diabetic BKS $(\mathrm{db} / \mathrm{db})$ mice. For this end, histological hepatic steatosis and biomarkers of liver injury were studied in addition to body weight management, glycaemic and dyslipidemia biomarkers.

\section{Materials and Methods}

\section{Materials}

Glucevia ${ }^{\circledR}$ (product code EA149251) is a natural extract of Fraxinus excelsior L. derived from seeds/fruits standardized to $10 \%$ Nuzhenide and Gl3 (US 8293292). The extract was supplied by Naturex S.A. (Avignon, France).

\section{Animal study design}

This study was carried out at the Laboratory Animals Service of the SAI (Servicio de Apoyo a la Investigación/Research Support Service, with license number REGAES 300305440012 at the University of Murcia) in compliance with European Union norms for the protection of animals used in experimentation (2010/63/UE). All experiments were approved by the Bioethics Committee of the University. Animals were housed in cages $(480 \times 270 \times 200 \mathrm{~cm})$, in a controlled $12 / 12 \mathrm{~h} \mathrm{light} /$ darkness cycle room at $22^{\circ} \mathrm{C}$ and received food and water ad libitum.

Twenty diabetic mutant female mice BKS. BKS ++ Lepr $\mathrm{db}(\mathrm{db} / \mathrm{db})$ from Harlan Laboratories (Barcelona, Spain), aged 5 weeks, with mean body weight $33 \pm 3 \mathrm{~g}$, were randomly assigned to the following groups: (1) a control group that received standard chow (control, $n=10$ ) and (2) a Glucevia ${ }^{\circledR}$ treated group $(n=10)$ that received a standard chow with $0.07 \%(\mathrm{w} / \mathrm{w})$ Glucevia $^{\circledR}$. Diet and tap water were administered ad libitum. The standard chow (PanLab, Barcelona) had the following composition: $14.3 \%$ protein, $4.0 \%$ fat, $48.0 \%$ carbohydrate, $4.1 \%$ crude fiber, $18.0 \%$ neutral detergent fiber and $4.7 \%$ ash; energy density, $2.9 \mathrm{kcal} / \mathrm{g}$ ). The dose correspond to an initial $170 \mathrm{mg}$ of extract per $\mathrm{kg}$ body weight per day, approximately $13,7 \mathrm{mg}$ per $\mathrm{kg}$ body weight HED, similar to the dose used during the clinical trials conducted $[4,5]$. Dietary intervention lasted for 28 weeks. Body weight, food and water intake were recorded throughout the study. At the end of the experimental period, over-night fasted animals were euthanatized by $\mathrm{CO}_{2}$ chamber. Livers were taken and weighed prior to hepatic steatosis histological studies.

\section{Biochemical analyses}

Blood samples were taken from the superficial temporal vein of the BSK mice. All biochemical parameters were analyzed using the multi- channel auto-analyzer Olympus A400 (Olympus, Hamburg, Germany). Serum insulin was determined by enzyme-linked immunosorbent assay (mouse insulin ELISA kit supplied by Zeleste Diagnostic Etyca Research, Barcelona) and HOMA-IR was calculated as described by Matthews et al. [13]. The extent of liver injury was assessed by determination of alkaline phosphatase (ALP), total bilirubin, creatinine, serum alanine aminotransferase (ALT) and serum aspartate amino transferase (AST) using the multi-channel autoanalyzer Olympus A400.

\section{Liver histopathology}

The liver morphology was visualized by hematoxylin and eosin (H\&E) staining. Liver samples were rapidly fixed in $10 \%$ formaldehyde and embedded in paraffin. Paraffin sections were cut at $3 \mu \mathrm{m}$ and stained with H\&E, using standard procedures. For the detection of lipid deposition in liver, liver section were prepared from frozen liver and stained with oil red O as previously reported [14]. Digitized H\&E and oil red $\mathrm{O}$-stained slides were analyzed with image analysis software to obtain a quantitative histologic measurement of steatosis using a Leica DM 600B microscope, with Leica DFC280 camera and a Leica image analysis program supplied by Leica Microsystems AG (Solms, Germany). Six random images at x40 magnification for each liver biopsy were taken to ensure a representative sample for each specimen. A histogram of pixel intensity was generated from the image, the area was measured and the results were expressed as fat percentage by area. Liver steatosis was blindly evaluated by two expert liver pathologists according to the Kleiner and Brunt classification [15]: Grade $0(<5 \%)$, $1(5-33 \%), 2(34-66 \%), 3(>67 \%)$. In addition, the size of the fat droplets was calculated to identify the percentage of microvesicular and macrovesicular steatosis. Microvesicular steatosis was defined as a diameter $\leq 15 \mu \mathrm{m}[16]$.

\section{Statistical analysis}

Data were analyzed using the SPSS version 19.0 statistical package (SPSS ${ }^{\circledR}$ Inc., Chicago, IL, USA). A descriptive study was made of each variable. All results were expressed as mean \pm standard error of the mean. Statistical comparisons of groups were conducted using the Student's t-test or one way ANOVA with Bonferroni post-hoc analysis. Statistical significance was set at $\mathrm{p}<0.05$.

\section{Results}

\section{Growth parameters}

The two groups of BSK db/db mice did not differ in their initial body weight. Food intake was significantly higher $(\mathrm{p}<0.05)$ in animals treated with Glucevia ${ }^{\circledR}$ than in their control counterparts and remained constant during the study $(7.09 \pm 0.53$ vs. $4.99 \pm 0.72 \mathrm{~g} / \mathrm{mouse} /$ day $)$. The global health status of animals treated with Glucevia ${ }^{\circledR}$ was better than in control group; the mice were more active and were eating more. However, after 28 weeks of administration, animals treated with Glucevia $^{\circledR}$ gained less weight than control group (Table 1). Total body weight gain were respectively $17.91 \mathrm{~g}$ vs $13.1 \mathrm{~g}$ for control group and Glucevia ${ }^{\circledR}$ group $(p=0.07)$. There were no significant differences in the consumption of water between the control and the treated groups (3.23 \pm 0.41 vs. $3.49 \pm 0.27 \mathrm{~mL} /$ mouse/day).

\section{Plasmatic markers of type 2 diabetes}

A decrease in fasting blood glucose (FBG) by $9 \%$ was observed in animals treated with Glucevia ${ }^{\circledR}$ compared with placebo after 7 months, without statistically significance. Nevertheless, at the end of the experiment, Glucevia $\oplus$ reduced fasting plasma insulin levels by $22 \%$ 
Citation: Garcia FG, Flanagan J, Molina OG, Vivo VV, Carrillo NG, et al. (2015) Preventive Effect of a Fraxinus Excelsior L Seeds/Fruits Extract on Hepatic Steatosis in Obese Type 2 Diabetic Mice. J Diabetes Metab 6: 527. doi:10.4172/2155-6156.1000527

Page 3 of 5

\begin{tabular}{|c|c|c|}
\hline & Control & Glucevia ${ }^{\circledR}$ \\
\hline Initial Body Weight $(\mathrm{g})$ & $28.59 \pm 1.83$ & $28.69 \pm 2.00$ \\
\hline Final Body weight $(\mathrm{g})$ & $46.50 \pm 6.69$ & $41.82 \pm 8,63$ \\
\hline Initial Food intake (g/mouse/day) & $5.37 \pm 1.01$ & $7.05 \pm 1.87^{*}$ \\
\hline Final Food intake (g/mouse/day) & $4.18 \pm 0.97$ & $6.79 \pm 1.52^{*}$ \\
\hline
\end{tabular}

The value are expressed as mean \pm SE for 10 mice

*Significant $(p<0.05)$ difference between the control and Glucevia $®$ groups

Table 1: The effect of Glucevia® on growth parameter in BKS db/db mice.

compared with control group mice $(\mathrm{p}<0.05)$ equivalent a $46 \%$ decrease of the HOMA-IR parameter in treated animals (Table 2).

Total-cholesterol and HDL-C serum levels were not found to be different between the control and Glucevia ${ }^{\circ}$ groups at the end of the study $\left(143.63 \pm 24.77\right.$ and $88.00 \pm 21.07{\mathrm{mg} . \mathrm{dl}^{-1}}^{\mathrm{v}}$ vs. $133.12 \pm 36.43$ and $88.81 \pm 35.05 \mathrm{mg} \cdot \mathrm{dl}^{-1}$ respectively). However, significant changes in plasmatic triglycerides levels were observed at end point depending on the treatment $(264.83 \pm 49.36$ vs. $162.72 \pm 73.90$ for control and Glucevia ${ }^{\circledR}$ respectively), which corresponds to a $33.4 \%$ reduction induced by Glucevia ${ }^{\circledR}$ treatment $(\mathrm{p}<0.05)$. Chronic administration of the extract did not modify adiponectin plasma levels $(13.14 \mu \mathrm{g} / \mathrm{ml} v \mathrm{v}$. $10.67 \mu \mathrm{g} / \mathrm{m}$ in Glucevia ${ }^{\circledR}$ and control groups respectively).

\section{Markers of NAFLD}

The relative liver weight was found to be $18 \%$ lower in the Glucevia ${ }^{\circledR}$ treated $\mathrm{db} / \mathrm{db}$ mice than in the control mice (Table 3). To estimate liver injury, ALP, AST and ALT biomarkers, total bilirubin and creatinine were compared between groups at the end of the experiment. The chronic administration of Glucevia ${ }^{\circledR}$ led to decrease plasma level of ALP compared to control group $(116.33 \pm 34.12 \mathrm{U} / \mathrm{l}$ vs. $87.38 \pm 30.93$ $\mathrm{U} / \mathrm{l} ; \mathrm{p}<0.05)$ while no difference in total bilirubin and creatinine was observed. Furthermore, the AST/ALT ratio was significantly lower in the Glucevia ${ }^{\circledR}$-treated group compared to control group mice (1.56 \pm 0.52 vs. $2.91 \pm 1.85 ; \mathrm{p}<0.05)$. Neither inflammation nor fibrosis were detected in either groups of mice. Only a slight lobular inflammation and a diffuse hepatocytes ballooning were observed in the livers of the control group. Ballooning degeneration was less pronounced and lobular inflammation was almost absent in treated animals, while microvesicular steatosis was observed and had a closed prevalent disease grade $2(28 \%)$ according to Kleiner and Brunt classification [15]. In Glucevia ${ }^{\circledR}$ treated mice, steatosis was markedly reduced by $54 \%$ in hepatocyte fat content $(\mathrm{p}<0.05)$ compared to controls (Figure 1).

\section{Discussion}

In the current study, we provide for the first time evidence supporting the beneficial effect of Glucevia ${ }^{\mathbb{B}}$ to prevent hepatic steatosis in a diabetic animal model. The liver plays a key role in metabolic homeostasis, not only on gluconeogenesis and glycogen storage, but also thanks to its ability to control massive amounts of lipogenesis and cholesterol synthesis and secretion [17]. The genesis of steatosis is closely related to the development of obesity and particularly insulin resistance (IR), a near universal finding in patients with NAFLD $[18,19]$. Genetic leptin-resistant BKS $(\mathrm{db} / \mathrm{db})$ mice were choose to conduct this study because they suffer from hyperphagia and develop multiple metabolic and hormonal disorders, including NAFLD, and shares many features with human metabolic syndrome [20,21]. It is characteristic for individuals with type 2 diabetes to manifest a dyslipidemia of elevated triglyceride, reduced HDL-C, and small, dense LDL-C composition, a pattern that has also been related to obesity and IR [22]. In our study, although total cholesterol and HDL-C levels were found similar between the two groups at the end of the study, serum triglyceride concentration was statistically decreased in Glucevia ${ }^{\circledR}$ treated animals. This result in concomitant with our previous finding in Zucker rats fed with the same extract [12]. Steatosis occurs when the rate of import or synthesis of fatty acids by hepatocytes exceeds the rate of export or catabolism [23]. Dyslipidemia as a predictor of NAFLD is unclear, but triglyceride level of $1.7 \mathrm{mmol} / \mathrm{L}$ (equivalent to $150 \mathrm{mg} / \mathrm{dl}$ ) or greater have been found to be a significant predictors of septal fibrosis in overweight subjects [24]. Final triglycerides levels in treated mice $(162 \mathrm{mg} / \mathrm{dl})$ were quite closed to this predictive value while animals control exhibited 1.8 times more triglycerides levels $(265 \mathrm{mg} / \mathrm{dl})$. Consistent with the observed reduction of triglycerides, hepatomegaly was lower (18\%) in the treated group compared to the

\begin{tabular}{|c|c|c|}
\hline & Control & Glucevia ${ }^{\circledR}$ \\
\hline Initial Fasting Blood Glucose $(\mathrm{mg} / \mathrm{dl})$ & $202.17 \pm 28.39$ & $202.00 \pm 56.20$ \\
\hline Final Fasting Blood Glucose $(\mathrm{mg} / \mathrm{dl})$ & $791.25 \pm 140.44$ & $726.31 \pm 127.63$ \\
\hline Insulin $(\mathrm{mU} / \mathrm{L})$ & $5.60 \pm 0.82$ & $4.39 \pm 1.50^{\star}$ \\
\hline HOMA-IR & $9.55 \pm 1.33$ & $5.36 \pm 2.53^{\star}$ \\
\hline Total cholesterol $(\mathrm{mg} / \mathrm{dl})$ & $143.63 \pm 24.77$ & $133.12 \pm 36.43$ \\
\hline HDL-C $(\mathrm{mg} / \mathrm{dl})$ & $88.00 \pm 21.07$ & $88.81 \pm 35.05$ \\
\hline Triglycerides $(\mathrm{mg} / \mathrm{dl})$ & $264.83 \pm 49.35$ & $162.72 \pm 73.90^{\star}$ \\
\hline Adiponectin $(\mu \mathrm{g} / \mathrm{ml})$ & $10.67 \pm 1.79$ & $13.14 \pm 0.06$ \\
\hline
\end{tabular}

The value are expressed as mean \pm SE for 10 mice

*Significant $(p<0.05)$ difference between the control and Glucevia® groups

Table 2: The effect of Glucevia ${ }^{\circledR}$ on plasmatic markers in BKS $\mathrm{db} / \mathrm{db}$ mice.

\begin{tabular}{|c|c|c|}
\hline & Control & Glucevia ${ }^{\circledR}$ \\
\hline Liver weight $(\mathrm{g})$ & $2.94 \pm 0.86$ & $2.43 \pm 0.35$ \\
\hline Liver weight $(\mathrm{g} / 100 \mathrm{~g}$ bw) & $6.35 \pm 0,57$ & $6.35 \pm 1.23$ \\
\hline ALP $(\mathrm{U} / \mathrm{l})$ & $116.33 \pm 34.12$ & $87.38 \pm 30.93^{*}$ \\
\hline Total Bilirubin $(\mathrm{mg} / \mathrm{dl})$ & $0.28 \pm 0.04$ & $0.29 \pm 0.04$ \\
\hline Creatinine $(\mathrm{mg} / \mathrm{dl})$ & $0.25 \pm 0.05$ & $0.24 \pm 0.05$ \\
\hline AST/ALT quotient & $2.91 \pm 1.85$ & $1.56 \pm 0.52^{*}$ \\
\hline Steatosis $(\%)$ & $28.19 \pm 13.65$ & $12.59 \pm 6.81^{*}$ \\
\hline
\end{tabular}

The value are expressed as mean \pm SE for 10 mice

*Significant $(p<0.05)$ difference between the control and Glucevia ${ }^{*}$ groups

Table 3: The effect of Glucevia ${ }^{\circledR}$ on NAFLD in BKS db/db mice.
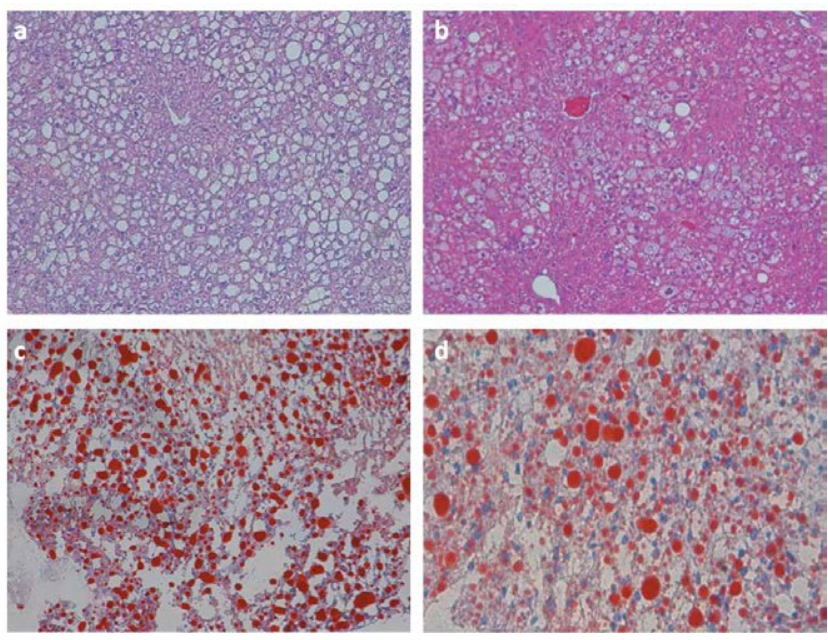

Figure 1: a) H\&E stained slide from control group showing intense macrovesicular steatosis; b) H\&E stained slide from Glucevia ${ }^{\circledR}$ treated mouse showing steatosis; Oil red O-stained slides from c) control group and d) treated animals. 
control group. In non-diabetic overweight/obese healthy subjects, the administration of Glucevia ${ }^{\circledR}$ for 3 weeks resulted in fat mass decrease and an improvement of adiposity related markers as adiponectin:leptin ratio, but no change was observed for plasmatic triglycerides between groups [5]. Extract supplementation over a long period should be required to lead to an improvement of plasma triglycerides level. Due to imbalance in energy consumption, impairment in fatty acid metabolism is closely related to fatty liver. Nuzhenide and GI3, the principal bioactive compounds present in Glucevia ${ }^{\circledR}$, have been shown to activate the peroxisome proliferator-activated receptor PPAR $\alpha$ that serves a critical role in the gene regulatory control of cellular lipid metabolic pathways [25]. Isolated secoiridoid glucosides, excelside A and excelside B (compounds isolated from a methanolic extract of Fraxinus excelsior L.) were also found to inhibit differentiation of 3T3L1 mouse embryonic fibroblasts into adipocytes [6]. This agrees with a recent study where associated-lipogenic transcriptional factors and numerous lipogenic enzymes were shown to be suppressed by mulberry leaf polyphenol extracts, leading to reduced hepatic lipid accumulation in hepatocytes culture [26]. It is important to point out that our study was conducted over 7 months and that Glucevia ${ }^{\circledR}$ not only prevented hepatosteatosis but also showed healthy liver improvement. Elevated transaminases levels are commonly observed in NAFLD stage and an AST:ALT ratio - a standard biomarkers of a healthy liver - higher than 1 predicts the presence of fibrosis [27]. The magnitude of the ASL:ALT ratio was found twice as high in control group compared with treated mice. Interestingly, the plasma level of ALP was shown to be improved in Glucevia ${ }^{\circledR}$ treated mice compared with control mice. In a previous study, a Fraxinus excelsior extract was described to increase bile secretion and the detoxifying function of the liver [28]. Our results show that total bilirubin and creatinine were similar in the two groups of mice and plasma levels suggests an early stage of fatty liver disease, in agreement with the lack of fibrobis observed in tissue sample. A human evaluation of Glucevia ${ }^{\circledR}$ was done in a doubleblind, placebo-controlled parallel study of 100 healthy volunteers and all the liver variables assessed - AST, ALT, gamma-glutamyltransferase (GGT), alkaline phosphatase, total bilirubin, creatinine - revealed the safety of the extract on the liver [29]. Although we have not observed notable signs of inflammation and fibrosis in the liver samples, our histopathological study along with the liver safety biomarkers clearly indicate a more advanced stage of NAFLD in control animals versus treated animals.

The effect of Glucevia ${ }^{\circledR}$ on FBG remains unclear as no significant reduction in FBG was observed between groups. However, the insulin sensitizer capacity of the extract is once again illustrated. Our results showed an insulin response disproportionally increased in control group vs. treated animals for similar FBG. These effect could be due to enhanced glucose uptake in the liver and skeletal muscle as was previously described for another iridoid glycoside extracted from the roots of Rehmannia glutinosa [30]. Ibarra et al. [7] reported that mice fed a high-fat diet and administered Glucevia ${ }^{\mathbb{B}}$ also decreased significantly fasting insulin levels at the end of the 16-week study compared to mice fed a high-fat diet alone. Furthermore, the extract was found to maintain a similar insulin area under the curve, concomitant with a better glucose tolerance after an OGTT in acute clinical trial on healthy subjects [4]. In the current study, the HOMAIR parameter was significantly lower in the treated animals, implying reduced insulin-resistance. Alteration in the insulin signaling pathway lead to accumulation of fatty acids and lipid metabolites as suggested by Zhang et al. [31]. The improvement of HOMA-IR in treated animals may delay the imbalance between fatty acid uptake and oxidation responsible for lipid accumulation in the liver. In accordance with this founding, the administration of iridoid glucoside isolated from Vitex negundo leaves has recently been shown to improve glucose uptake as well as fatty liver incidence in a type 2 diabetic-induced mouse model [32].

The processes by which steatohepatitis evolves from hepatic steatosis are not fully understood, but the initiation and perpetuation of cell injury in NAFLD is associated with the increase of free radicals and the depletion of endogenous anti-oxidant defense both in human and rodents [33]. Developing effective therapies for treating steatosis is necessary, and discovering nutrients that can reduce the risk of NAFLD would be useful [34]. In conclusion, this study suggests that long term administration Glucevia ${ }^{\mathbb{}}$ prevents hepatic steatosis in $\mathrm{db} / \mathrm{db}$ mice, probably mediated by glucose homeostasis and insulin resistance improvements. Further studies are necessary to generate mechanistic insight on steatosis prevention and to identify companion biomarkers before investigating the use of Glucevia ${ }^{\circledR}$ to prevent NAFLD in patients suffering for diabetes.

\section{Acknowledgments}

This work was supported by the CENIT Programme from the Spanish Government (SENIFOOD project).

Naturex is involved in the research/development and marketing/sales of Glucevia ${ }^{\circledR}$ as an ingredient for the food, cosmetic, and nutraceutical industries.

\section{References}

1. Jouad H, Haloui M, Rhiouani H, El Hilaly J, Eddouks M (2001) Ethnobotanical survey of medicinal plants used for the treatment of diabetes, cardiac and renal diseases in the North centre region of Morocco (Fez-Boulemane). J Ethnopharmacol 77: 175-182.

2. Eddouks M, Maghrani M (2004) Phlorizin-like effect of Fraxinus excelsior in normal and diabetic rats. J Ethnopharmacol 94: 149-154.

3. Maghrani M, Zeggwagh NA, Lemhadri A, El Amraoui M, Michel JB, et al. (2004) Study of the hypoglycaemic activity of Fraxinus excelsior and Silybum marianum in an animal model of type 1 diabetes mellitus. J Ethnopharmacol 91: 309-316.

4. Visen P, Saraswat B, Visen A, Roller M, Bily A, et al. (2009) Acute effects of Fraxinus excelsior $L$. seed extract on postprandial glycemia and insulin secretion on healthy volunteers. J Ethnopharmacol 126: 226-232.

5. Zulet MA, Navas-Carretero S, Lara y Sánchez D, Abete I, Flanagan J, et al. (2014). A Fraxinus excelsior L. seeds/fruits extract benefits glucose homeostasis and adiposity related markers in elderly overweight/obese subjects: A longitudinal, randomized, crossover, double-blind, placebocontrolled nutritional intervention study. Phytomedicine 21:1162-1169.

6. Bai N, He K, Ibarra A, Bily A, Roller M, et al. (2010) Iridoids from Fraxinus excelsior with adipocyte differentiation-inhibitory and PPARalpha activation activity. J Nat Prod 73: 2-6.

7. Ibarra A, Bai N, He K, Bily A, Cases J, et al. (2011) Fraxinus excelsior seed extract FraxiPureâ, $\phi$ limits weight gains and hyperglycemia in high-fat dietinduced obese mice. Phytomedicine 18: 479-485.

8. Sass DA, Chang P, Chopra KB (2005) Nonalcoholic fatty liver disease: a clinical review. Dig Dis Sci 50: 171-180.

9. Targher G, Bertolini L, Padovani R, Rodella S, Tessari R, et al. (2007) Prevalence of nonalcoholic fatty liver disease and its association with cardiovascular disease among type 2 diabetic patients. Diabetes Care 30 1212-1218.

10. World Gastroenterology Organisation Global Guidelines (2012) NAFLD/NASH A global review.

11. Blaak EE, Antoine JM, Benton D, Björck I, Bozzetto L, et al. (2012) Impact of postprandial glycaemia on health and prevention of disease. Obes Rev 13 923-984.

12. Montó F, Arce C, Noguera MA, Ivorra MD, Flanagan J, et al. (2014) Action of an extract from the seeds of Fraxinus excelsior $L$ on metabolic disorders in hypertensive and obese animal models. Food Funct 5: 786-796. 
Citation: Garcia FG, Flanagan J, Molina OG, Vivo VV, Carrillo NG, et al. (2015) Preventive Effect of a Fraxinus Excelsior L Seeds/Fruits Extract on Hepatic Steatosis in Obese Type 2 Diabetic Mice. J Diabetes Metab 6: 527. doi:10.4172/2155-6156.1000527

Page 5 of 5

13. Matthews DR, Hosker JP, Rudenski AS, Naylor BA, Treacher DF, et al. (1985) Homeostasis model assessment: insulin resistance and beta-cell function from fasting plasma glucose and insulin concentrations in man. Diabetologia 28 412-419.

14. Fowler SD, Greenspan P (1985) Application of Nile red, a fluorescent hydrophobic probe, for the detection of neutral lipid deposits in tissue sections: comparison with oil red O. J Histochem Cytochem 33: 833-836.

15. Kleiner DE, Brunt EM (2012) Nonalcoholic fatty liver disease: pathologic patterns and biopsy evaluation in clinical research. Semin Liver Dis 32: 3-13.

16. Zaitoun AM, Al Mardini H, Awad S, Ukabam S, Makadisi S, et al. (2001) Quantitative assessment of fibrosis and steatosis in liver biopsies from patients with chronic hepatitis C. J Clin Pathol 54: 461-465.

17. Gregor MF, Hotamisligil GS (2011) Inflammatory mechanisms in obesity. Annu Rev Immunol 29: 415-445.

18. Fruci B, Giuliano S, Mazza A, Malaguarnera R, Belfiore A (2013) Nonalcoholic Fatty liver: a possible new target for type 2 diabetes prevention and treatment. Int J Mol Sci 14: 22933-22966.

19. Salamone F, Galvano F, Marino Gammazza A, Paternostro C, Tibullo D, et al. (2012) Silibinin improves hepatic and myocardial injury in mice with nonalcoholic steatohepatitis. Dig Liver Dis 44: 334-342.

20. Lee GH, Proenca R, Montez JM, Carroll KM, Darvishzadeh JG, et al. (1996) Abnormal splicing of the leptin receptor in diabetic mice. Nature 379: 632-635.

21. Anstee QM, Goldin RD (2006) Mouse models in non-alcoholic fatty liver disease and steatohepatitis research. Int J Exp Pathol 87: 1-16.

22. Dickson-Humphries T, Bottenberg B, Kuntz S (2013) Lipoprotein abnormalities in patients with type 2 diabetes and metabolic syndrome. JAAPA 26: 13-18.

23. Bradbury MW, Berk PD (2004) Lipid metabolism in hepatic steatosis. Clin Liver Dis 8: 639-67, xi.

24. Ratziu V, Giral P, Charlotte F, Bruckert E, Thibault V, et al. (2000) Liver fibrosis in overweight patients. Gastroenterology 118: 1117-1123.
25. Finck BN, Bernal-Mizrachi C, Han DH, Coleman T, Sambandam N, et al. (2005) A potential link between muscle peroxisome proliferator- activated receptoralpha signaling and obesity-related diabetes. Cell Metab 1: 133-144.

26. Wu CH, Chen SC, Ou TT, Chyau CC, Chang YC, et al. (2013) Mulberry leaf polyphenol extracts reduced hepatic lipid accumulation involving regulation of adenosine monophosphate activated protein kinase and lipogenic enzymes. J Funct Foods 5: 1620-1632.

27. Dixon JB, Bhathal PS, O'Brien PE (2001) Nonalcoholic fatty liver disease: predictors of nonalcoholic steatohepatitis and liver fibrosis in the severely obese. Gastroenterology 121: 91-100

28. Kostova I, lossifova T (2007) Chemical components of Fraxinus species. Fitoterapia 78: 85-106.

29. Flanagan J, Meyer M, Pasamar MA, Ibarra A, Roller M, et al. (2013) Safety evaluation and nutritional composition of a Fraxinus excelsior seed extract, FraxiPure. Food Chem Toxicol 53: 10-17.

30. Shieh JP, Cheng KC, Chung HH, Kerh YF, Yeh CH, et al. (2011) Plasma glucose lowering mechanisms of catalpol, an active principle from roots of Rehmannia glutinosa, in streptozotocin-induced diabetic rats. J Agric Food Chem 59: 3747-3753.

31. Zhang L, Keung W, Samokhvalov V, Wang W, Lopaschuk GD (2010) Role of fatty acid uptake and fatty acid beta-oxidation in mediating insulin resistance in heart and skeletal muscle. Biochim Biophys Acta 1801: 1-22.

32. Sundaram R, Shanthi $P$, Sachdanandam $P(2013)$ Effect of iridoid glucoside on plasma lipid profile, tissue fatty acid changes, inflammatory cytokines, and GLUT4 expression in skeletal muscle of streptozotocin-induced diabetic rats. Mol Cell Biochem 380: 43-55.

33. Videla LA, Rodrigo R, Orellana M, Fernandez V, Tapia G, et al. (2004) Oxidative stress-related parameters in the liver of non-alcoholic fatty liver disease patients. Clin Sci (Lond) 106: 261-268.

34. Tsuruta Y, Nagao K, Kai S, Tsuge K, Yoshimura T, et al. (2011) Polyphenolic extract of lotus root (edible rhizome of Nelumbo nucifera) alleviates hepatic steatosis in obese diabetic db/db mice. Lipids Health Dis 10: 202. 